2006-01-01

\title{
Including Embodied Energy Considerations at the Conceptual Stage of Building Design
}

\author{
Y. Yohanis \\ University of Ulster \\ Brian Norton \\ Technological University Dublin
}

Follow this and additional works at: https://arrow.tudublin.ie/dubenart

Part of the Heat Transfer, Combustion Commons

\section{Recommended Citation}

Yohanis, Y., Norton, B. (2006). Including Embodied Energy Considerations at the Conceptual Stage of Building Design. Proceedings of the Institution of Mechanical Engineers, Part A, Journal of Power and Energy, Vol. 220, no. 3, pp.271-289. doi:10.1243/095765006X76009

This Article is brought to you for free and open access by the Dublin Energy Lab at ARROW@TU Dublin. It has been accepted for inclusion in Articles by an authorized administrator of ARROW@TU Dublin. For more information, please contact arrow.admin@tudublin.ie, aisling.coyne@tudublin.ie,gerard.connolly@tudublin.ie.

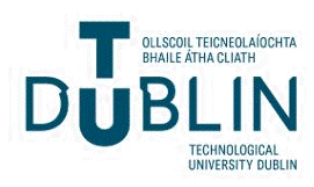




\title{
Natural Convection in an Internally Finned Phase Change Material Heat Sink for the Thermal Management of Photovoltaics
}

\author{
M.J. Huang $^{1 *}$, P.C. Eames ${ }^{2}$, B. Norton ${ }^{3^{*}}$ and N.J. Hewitt ${ }^{1}$ \\ ${ }^{1}$ Centre for Sustainable Technologies, School of Built Environment, University of Ulster, \\ Jordanstown, Co. Antrim, N.Ireland, BT37 0QB, UK \\ m.j.huang@exeter.ac.uk \\ ${ }^{2}$ Centre for Renewable Energy Systems Technology, Department of Electronic and Electrical \\ Engineering, Loughborough University, Leicestershire, LE11 3TU, UK \\ ${ }^{3}$ Dublin Energy Lab., Focas Institute, Dublin Institute of Technology, Dublin 8, Ireland.
}

${ }^{*}$ Member of ISES

\begin{abstract}
Elevated operating temperatures reduce the solar to electrical conversion efficiency of building integrated photovoltaic devices (BIPV). Phase change materials (PCM) can be used to passively limit this temperature rise although their effectiveness is limited by their low thermal conductivities and by crystallization segregation during solidification. This paper presents an experimental evaluation of the effects of convection and crystalline segregation in a PCM as a function of efficiency of heat transfer within the finned PV/PCM system. The thermal performances of bulk PCM with crystallization segregation for different internal fin arrangements are presented. It is noted that the addition of internal fins improves the temperature control of the PV in a PV/PCM system.
\end{abstract}

Keywords: Phase change material; Building integrated photovoltaic; Convection.

\section{Introduction}

Elevated operating temperatures reduce the solar to electrical conversion efficiency of silicon photovoltaic devices [1](Ref?). Active heat dissipation using air or water cooling introduces costs associated with both pumping and increased system maintenance although these costs can be offset at least in part if the generated thermal energy can be utilised in the building.. The most common passive approach to heat dissipation involves a duct arranged behind the PV panel or its mounting system allowing natural convection and wind induced air-flow 
across the back of the PV panel. This is inherently limited due to the uncertainty of wind direction and pressure.

At an insolation of $750 \mathrm{Wm}^{-2}$ and ambient temperature of $23^{\circ} \mathrm{C}$, the $\mathrm{PV}$ cell temperature can rise to over $45^{\circ} \mathrm{C}$ [2]. When the average ambient temperature is over $23^{\circ} \mathrm{C}$ with incident solar radiation above $400 \mathrm{Wm}^{-2}$ conventional air-cooling arrangements are insufficient to maintain good PV performance. Concentrating PV systems have additional cooling requirements beyond these limits.

Phase change materials (PCM) can absorb/discharge a large amount of energy over a limited temperature range during phase change. PCMs are of interest for use in applications as diverse as thermal energy storage and the thermal management of systems as well as for active and passive cooling of electronic devices. The capacity of a PCM for energy storage and temperature control depends on its properties, heat transfer methods and system configuration. The properties of various PCMs, methods of heat transfer enhancement, design configurations of heat storage facilities as part of solar passive and active space heating systems, thermal energy storage systems and building applications have been the subject of recent reviews $[3,4,5]$. Paraffin and paraffin wax are both non-toxic and inert with most materials and do not pose a danger to either health or the environment. The more important technical barriers when using paraffin and paraffin wax for energy storage and temperature regulation are their low thermal conductivities $(\sim 0.2 \mathrm{~W} / \mathrm{mK})$ and the presence of impurities that cause heterogeneous nucleation over a temperature range. The low thermal conductivity frequently makes an anticipated level of thermal storage untenable within an acceptable time period.

An investigation of a PV/PCM system with a selection of metal fin configuration in the PCM to limit passively the temperature rise of BIPV has been conducted. The system is compared with conventional air-cooling arrangements both experimentally and using numerical 
simulation $[2,6]$. It has been found that using a PCM "RT27" with metal fins can significantly moderate the temperature rise of the PV in a PV/PCM system. In order to optimise the system, a detailed study to provide insight into the effect of fins on natural convection inside the system is required. Venkatesana, et al. [7] simulatied the paraffin crystal structure formed when wax deposits on an inner pipe wall. It was found that the crystallization of paraffin is determined by both the shear rates and cooling rates. With higher wax contents, the introduction of oscillatory motion not only promotes wax deposition, but also accelerates the crystal growth to achieve full wax deposition [8]. The effect of crystalline segregation on temperature regulation within the rectangular shape of a PV/PCM system is however not clear.

The effect of convection and crystalline segregation on the heat transfer efficiency within a PV/PCM system for PV temperature regulation was evaluated experimentally and is reported in this paper. The thermal performance of bulk PCM with crystallization segregation for different internal fin arrangements is also presented.

\section{Experimental Methods}

\subsection{Phase Change Materials Selection and PV/PCM Testing System Fabrication}

Three proprietary paraffin based PCMs were studied. Table 1 lists the thermophysical properties of Waksol A, RT27 and RT35 [9] [10]. To take account of volume expansion during melting, only $85 \%$ of the total volume of test system was filled with PCM.

The PV/PCM system, shown in Figure 1 was fabricated to study the effect of fins on the PV/PCM systems temperature control in relation to PCM porosity. The $5 \mathrm{~mm}$ aluminium front and back walls of the PV/PCM test system provided a high rate of heat transfer to the PCM. This was enhanced further by a series of demountable metal fins extending into the PCM from the front wall. The interior dimensions of the containers were $0.132 \mathrm{~m}$ long by 
$0.04 \mathrm{~m}$ depth by $0.3 \mathrm{~m}$ high. The upper and lower horizontal and the vertical end faces of the PV/PCM system were made of $0.012 \mathrm{~m}$ thick clear perspex through which the phase transition could be observed. $0.050 \mathrm{~m}$ thick polystyrene foam, thermal conductivity $0.027 \mathrm{Wm}^{-1} \mathrm{~K}^{-1}$ provided insulation on the top, bottom and side areas of the system. The insulation located on the vertical ends and top faces could be removed to enable observation of the system interior.

\subsection{Experimental Apparatus}

The experimental apparatus consisted of the PV/PCM experimental test system with variable fin spacings, a GR262 solar simulator lighting system, environmental chamber and an independently powered programmable data-acquisition device. The ambient temperature and temperatures both within and on the external surfaces of the PV/PCM systems were measured using $0.2 \times 10^{-3} \mathrm{~m}$ diameter T-type copper-constantan thermocouples calibrated to $\pm 0.1^{\circ} \mathrm{C}$ using a standard resistance-temperature detector. Ten T-type thermocouples equally distributed on the front and back surfaces of the PV/PCM system measured surface temperatures. Thirty one thermocouples were divided between seven levels within the PV/PCM system denoted by A to $\mathrm{G}$ at $30 \mathrm{~mm}$ intervals from the bottom to the top of the system as shown in Figure 2. Insolation was measured using a Kipp and Zonen class 2 pyranometer.

The data acquisition device collected and stored data from the thermocouples and pyranometer at 60 second intervals. The data from the data logging system was then transferred to a computer for analysis. The logger was located adjacent to the test system shaded from the simulated insolation. A chamber that could be cooled to below $-30^{\circ} \mathrm{C}$ was used for the PCM cooling tests.

\section{Results and discussions}




\subsection{Physical Structure of PCMs in the PV/PCM System with Melting and Solidification Cycle}

Convection in the melted liquid PCM plays an important role for PV/PCM system temperature control. Melting depends on parameters such as temperature, the inner physical structure of the PCM in the PV/PCM system and the cooling rate to the PCM. Convection in the system may be caused by [11]:

a) Forced convection resulting from imposed pressure gradients, electric, magnetic forces or movement of external surfaces surrounding the melt,

b) Buoyancy forces (natural convection) caused in the presence of gravity by density differences in the liquid resulting from temperature changes,

\section{c) Solidification shrinkage induced flows}

Solidification shrinkage is due to the change of density from liquid to solid PCM. This will further affect the cycle process of melting. Due to minimal impurities in the paraffin, crystallisation occurs at temperature below their natural phase change temperatures. The PCM first solidifies with a dense structure in the area adjacent to the cooling wall of the container, the effect of volume contraction when the PCM solidifies increases the PCM porosity in the centre of the bulk PCM.

In order to determine the affect of crystallisation in the PV/PCM system on the temperature regulation of the PV, three PCM samples (Table 1) have been tested. PCM RT27 and RT35 have same liquid density as PCM Waksol A, but their solid densities are higher than Waksol A. From Figure 3 it can be seen that for the same liquid volume, PCM RT35 has less solid volume than PCM Waksol A ,consequently the cavity formed in the RT35 sample was larger than that in the Waksol A sample. When using the paraffin based PCM for PV heat dissipation the cavity formed will increase the heat transfer resistance. During PCM melting, if there is no effective path to release the pressure due to volume expansion then system leakage can result. 
Metal fins in the PCMs increase the heat transfer inside the PCMs by increasing the surface area over which heat transfer to the PCM occurs and also act as a pressure release path for the melted PCM. Experimental investigations of a PV/PCM system with two fins in a horizontal position have been conducted. During PCM solidification there is shrinkage with gaps formed under the fins. From Figure 4 it can be seen that the horizontal fins increase heat transfer, however they also increase heat transfer resistance by blocking the movement of bubbles formed under the fins during PCM melting.

A PV/PCM system filled with 85\% RT27 with full size vertical metal fins was fabricated. The grooves on the interior walls of the PV/PCM system enabled the installation of a different number of fins up to a maximum of 32 fins on a $4 \mathrm{~mm}$ spacing The thickness of the steel fins was $0.5 \mathrm{~mm}$. Systems without fins and with fins at $8 \mathrm{~mm}, 12 \mathrm{~mm}$ and $24 \mathrm{~mm}$ spacings were investigated. The test rig was in a vertical position to mimic building integrated PV mounted on a wall.

\subsection{The Thermal Performance of PCM in PV/PCM System with Melting Process}

The PV temperature regulation provided by a PV/PCM system, depends on the thermal behaviour of the PCM in the PV/PCM system. Figure 5 presents the temperature variation with elapsed time along the height in the centre of the non-finned PV/PCM system. The average temperature on the front surface of the system under a simulated insolation of $750 \mathrm{Wm}^{-2}$ and an average surrounding ambient temperature of $19^{\circ} \mathrm{C}$ was measured. It was found that the temperature for a single plate could reach $63^{\circ} \mathrm{C}$ in 50 minutes. By using PCM RT27 with a melting temperature of $28^{\circ} \mathrm{C}$ with similar conditions, the PV/PCM system without fins reduced the temperature rise of the PV to $42^{\circ} \mathrm{C}$ at a time of 250 minutes. With continued energy input, the melting of PCM occurred from top to bottom (points G to A locations see Figure 2) with clear temperature stratification. Initially conduction was the 
dominant mode of heat transfer with a linear temperature increase with time. After 75 minutes, convective heat transfer ensued at points $\mathrm{G}$ and $\mathrm{F}$ as can be seen in Figure 5. Due to convection, the temperature increased sharply towards the front surface PV temperature while the temperatures in the solid phase locations (A, B, C, D and E) maintained their slow conduction-dominated increase. Convection led to increased heat dissipation from the upper molten PCM which caused the temperature of the molten PCM to increase slowly with time; this reduces the rate of temperature rise of the PV. With an increasing volume of molten PCM, the phase change temperature control effect was reduced. Points G and F at the upper section of the PV/PCM system have a higher temperature increase rate when in the solid phase than elsewhere in the system. This is due to the higher volumetric heat capacity of PCM that formed at the central top region during solidification. After melting occurred with natural-convection as indicated, the temperature at point $\mathrm{G}$ (30 $\mathrm{mm}$ below the top surface) showed a sharp increase in temperature with a large fluctuation. As the solid PCM occupies less volume than the liquid PCM, the shrinkage during solidification migrates from the cooler walls to the centre. This leaves a trough like structure when during melt is filled by expanding liquid PCM rising along the vertical heated surface and spilling into this trough.subsequently being cooled towards the surrounding solid PCM temperature (Figure 5).

\subsection{Thermal Performance Comparison for PV/PCM Systems with Different Fin Spacings}

A detailed analysis on the effects of fin spacings of 4 to $33 \mathrm{~mm}$ on the temperature control of the front surface of the PV/PCM system has been undertaken. Figure 6 shows the temperature variation with time from lower section point $A$ to upper section point $G$ in the centre of the PV/PCM system for different fin spacings. The temperature distribution inside of the system and on the front surface of the system with time for $750 \mathrm{Wm}^{-2}$ incident radiation is presented in Figures 6. When metal fins are added to the system the deep "funnel" cavity 
that forms in the upper PCM surface on solidification is divided into several small shallow funnel shape cavities between the fins. This enabled the stress developed during the phase change from solid to liquid to be released avoiding leakage from the PCM container. The increased number of fins reduced the formation of a deep cavity in the upper surface of the PCM and stabilized temperature fluctuations in the system.

Thermal stratification with height in the system indicates both that little mixing ensued and that the convective flow is laminar. When the fin spacing is more than $33 \mathrm{~mm}$, convection in the molten PCM combined with phase change of the solid PCM stabilised the temperature in the molten PCM. With the fraction of molten PCM increasing this stabilisation in the lower section of the system was reduced. At the lowest test point A, after the PCM at this location melted, fluid flow suddenly increased the temperature followed by sensible heat transfer. Fins increased the heat transfer inside the PCM and reduced the temperature rise on the front surface. With certain fin intervals convection increased the rate of heat transfer. With time the level of thermal stratification was reduced, the total stratification was also reduced for closer intervals between the fins. An increased number of fins however reduced convection. An increased number of fins also reduced the thermal stratification, leading to a more uniform temperature distribution in the PV/PCM system.

When the fin spacing is reduced, the fins prevent the onset of natural convection in the molten PCM and the melting process is predominantly determined by conductive heat transfer. Consequently, the time required for melting to occur is increased (see $24 \mathrm{~mm}$ and $12 \mathrm{~mm}$ ). When the fin spacing is reduced to below $12 \mathrm{~mm}$, the period over which phase change takes place is reduced and although the front surface temperature is more uniform the temperature after 150 minutes increases more rapidly.

\subsection{Effect of Fins on the Thermal Control for PV/PCM System}


The average temperatures on the front surface of the system with different fin spacings and no fins are shown in Figure 7. It can be seen that the fins effectively moderate the temperature rise on the front surface of the PV/PCM system. Fins reduce the temperature rise on the front surface and reduce the thermal stratification within the system. Fins however reduce the period over which temperature control is achieved, the increased weight due to the metal fins is also a potential problem. $\boldsymbol{A}_{\boldsymbol{r}}$ is defined to be the ratio of fin spacing to system depth. The relationship of $\boldsymbol{A}_{\boldsymbol{r}}$ to the period of temperature control and stable temperature control capacity for the PV/PCM system is presented in Figure 8 which can be used for system optimisation to design systems to meet required conditions.

\subsection{Effects of Rayleigh Number}

The Rayleigh number $\left(R_{a}\right)$ [12] describes the importance of buoyancy forces which drive convection compared to the diffusive processes (heat and momentum) which act to stabilise convection. Figure 9 shows that the Rayleigh numbers vary with metal fins spacing inside the system. After the PCM is fully melted, the Rayleigh number decreased when the fin spacing was reduced. With certain fin spacings the convection effect can increase the heat transfer rate. However when the fin spacing is less than $12 \mathrm{~mm}$ the convection effect is limited.

\section{Conclusions}

Elevated operating temperatures reduce the solar to electrical conversion efficiency of crystalline silicon photovoltaic (PV) cells. A PCM can be used to passively limit the PV temperature rise. However low heat transfer rates into the PCM and poor heat removal by the melted PCM need to be addressed if this method is to be used successfully. Methods of overcoming these barriers for using PCM for crystalline silicon PV temperature control are discussed in this paper. The PV temperature regulation provided by natural convection within 
the melted PCM in a PV/PCM system with differently spaced fins has been analysed in detail both theoretically and experimentally. The PCM melting process for finned and non-finned PV/PCM systems was the subject to detailed experimental evaluation.

This paper presents an experimental evaluation of the effects of convection and PCM crystalline segregation in the PCM on heat transfer within different internal finned PV/PCM systems. So using RT27 PCM with internal fins, the temperature rise of the PV can be reduced when compared to using a single flat aluminium plate. The improved fundamental understanding of the processes within the PV/PCM system provided by this work can be used to optimise the design of PV/PCM systems.

\section{Nomenclature}

\begin{tabular}{|c|c|c|}
\hline$C_{P}$ & Specific heat & $\mathrm{Jkg}^{-1} \mathrm{~K}^{-1}$ \\
\hline$g$ & Gravitational constant & $\mathrm{ms}^{-2}$ \\
\hline$k$ & Thermal conductivity & $\mathrm{Wm}^{-1} \mathrm{~K}^{-1}$ \\
\hline$\Delta T$ & $\begin{array}{l}\text { Temperature difference between the front and } \\
\text { rear wall of the system }\end{array}$ & ${ }^{\circ} \mathrm{C}$ \\
\hline$\beta$ & Volume expansion coefficient & \\
\hline$\Delta x$ & Depth of the PV/PCM system & $\mathrm{m}$ \\
\hline$\rho$ & Density & $\mathrm{kgm}^{-3}$ \\
\hline$\mu$ & Dynamic viscosity & $\mathrm{N} \cdot \mathrm{m}^{-2} \cdot \mathrm{s}$ \\
\hline$v=\frac{\mu}{\rho}$ & Kinematic viscosity & $m^{2} s^{-1}$ \\
\hline$R_{a} \equiv \frac{g \beta \Delta T \Delta x^{3}}{v \underline{K}}$ & & \\
\hline$\rho C_{P}$ & Rayleigh number & \\
\hline
\end{tabular}

\section{References}

[1] H. A. Weakliem, and D. Redfield, (1979). Temperature dependence of the optical properties of silicon. Journal of Applied Physics 50, 1491-1493

[2] M.J. Huang, P.C. Eames and B. Norton, (2006), Experimental Performance of Phase Change Materials for Limiting Temperature Rise Building Integrated Photovoltaics, Journal of Solar Energy, 80, pp. 1121-1130. 
[3] M. Kenisarin and K. Mahkamov, (2007). Solar energy storage using phase change materials, Renewable and Sustainable Energy Reviews, 11, pp. 1913-1965

[4] F. Agyenim, N. Hewitt, P. Eames, and M. Smyth, (2010) A review of materials, heat transfer and phase change problem formulation for latent heat thermal energy storage systems (LHTESS). Renewable and Sustainable Energy Reviews, 14 (2). pp. 615-628.

[5] R. Baetens B. Petter Jelle, A. Gustavsen, (2010). Phase change materials for building applications: A state-of-the-art review Review Article, Energy and Buildings, 42, 9, pp. 1361-1368.

[6] M.J. Huang, P.C. Eames and B. Norton, (2004), Thermal Regulation of BuildingIntegrated Photovoltaics Using Phase Change Materials, International Journal of Heat and Mass Transfer, 47, pp. 2715-2733

[7] R. Venkatesana,1, N.R. Nagarajanb, K. Pasoa,Y.-B.Yic, A.M. Sastryc, H.S. Foglera, (2005), The strength of paraffin gels formed under static and flow conditions, Chemical Engineering Science 60, pp. 3587 - 3598.

[8] Ismail Lukman, Westacott Robin E., Ni Xiongwei, (2008), On the effect of wax content on paraffin wax deposition in a batch oscillatory baffled tube apparatus, Chemical Engineering Journal 137, pp. 205-213

[9] Anon (a)., (2004). SCHUMANN SASOL data sheet. Schumann Sasol GmbH, Germany. [10] Anon (b)., (2007). Rubitherm data sheet. Rubitherm GmbH, Hamburg, Germany. [11] J.Banaszek, R. Domañski, M.Rebow and F. El-Sagier (1999). "Experimental study of solid liquid phase change in a spiral thermal energy storage unit." Applied Thermal Engineering 19(12): 1253-1277.

[12] F.P. Incropera and D.P. DeWitt, (1996). Fundamentals of Heat and Mass Transfer. $4^{\text {th }}$ Edn., John Wiley and Sons, New York, USA., ISBN-13: 978-0-471-794714. 

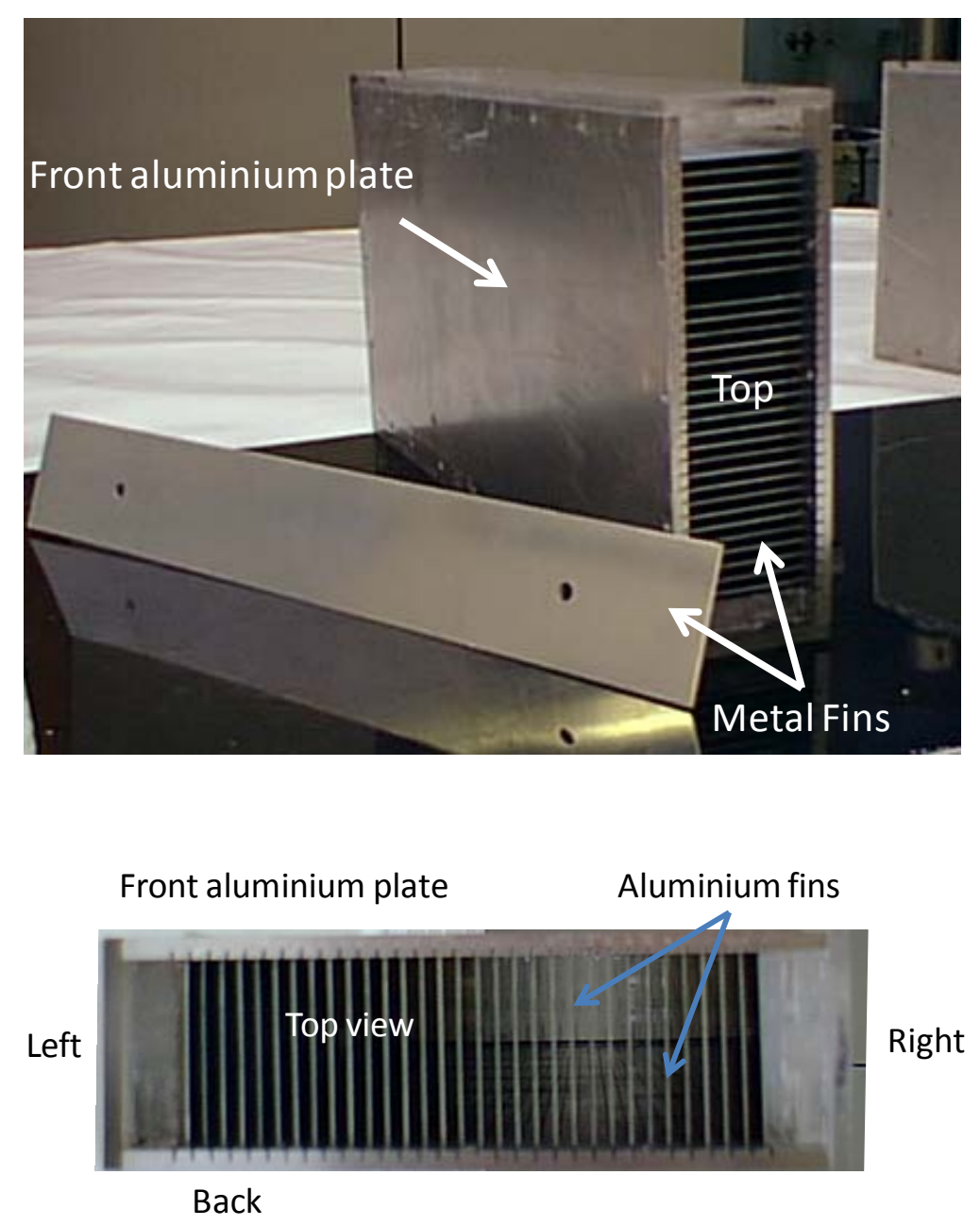

Figure $1 \quad$ PV/PCM assessment system with metal fins 


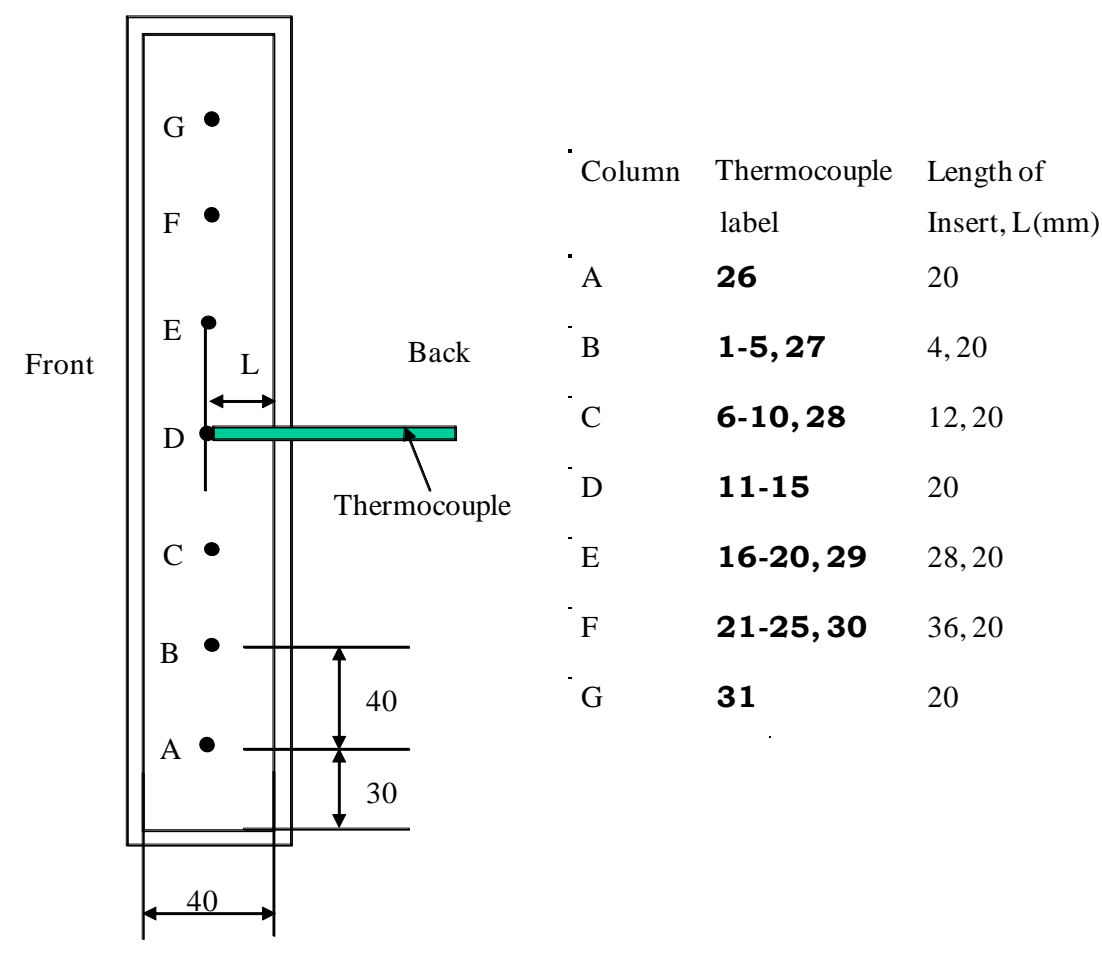

Figure 2 Distribution of thermocouples within experimental PV/PCM system

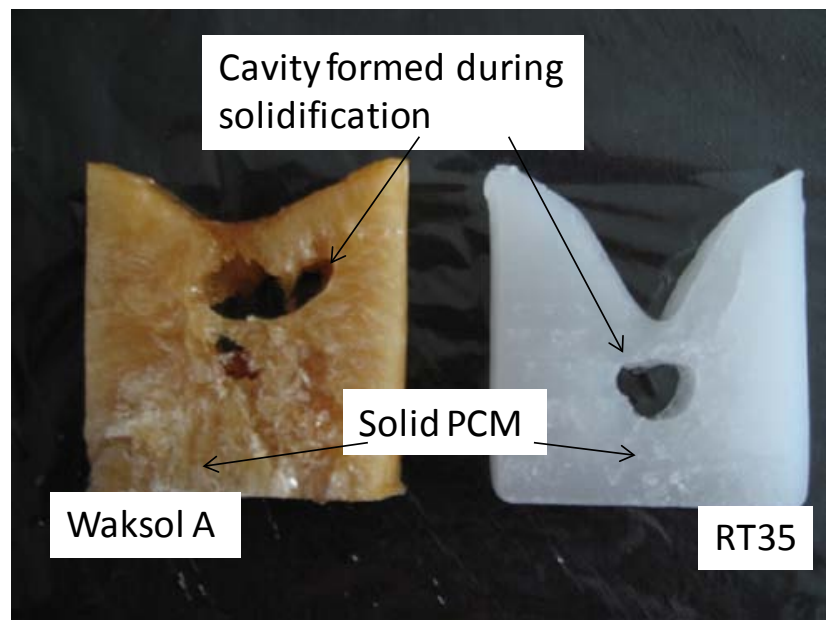

Figure 3 The porosity formed in the central bulk of PCM Waksol A and RT35 when solidification occurred using a $-25^{\circ} \mathrm{C}$ temperature. 


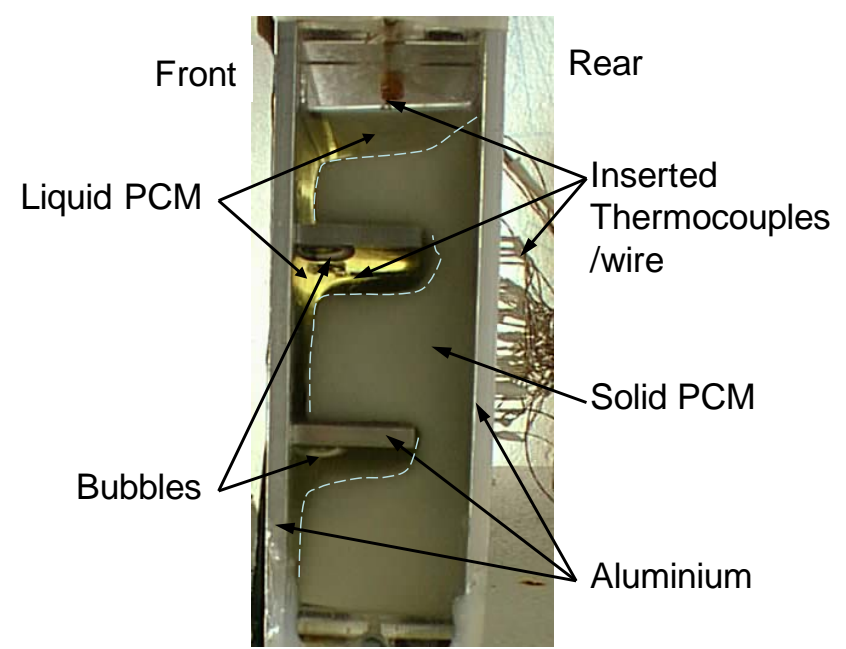

Figure $4 \quad$ Bubbles under fins formed during melting 


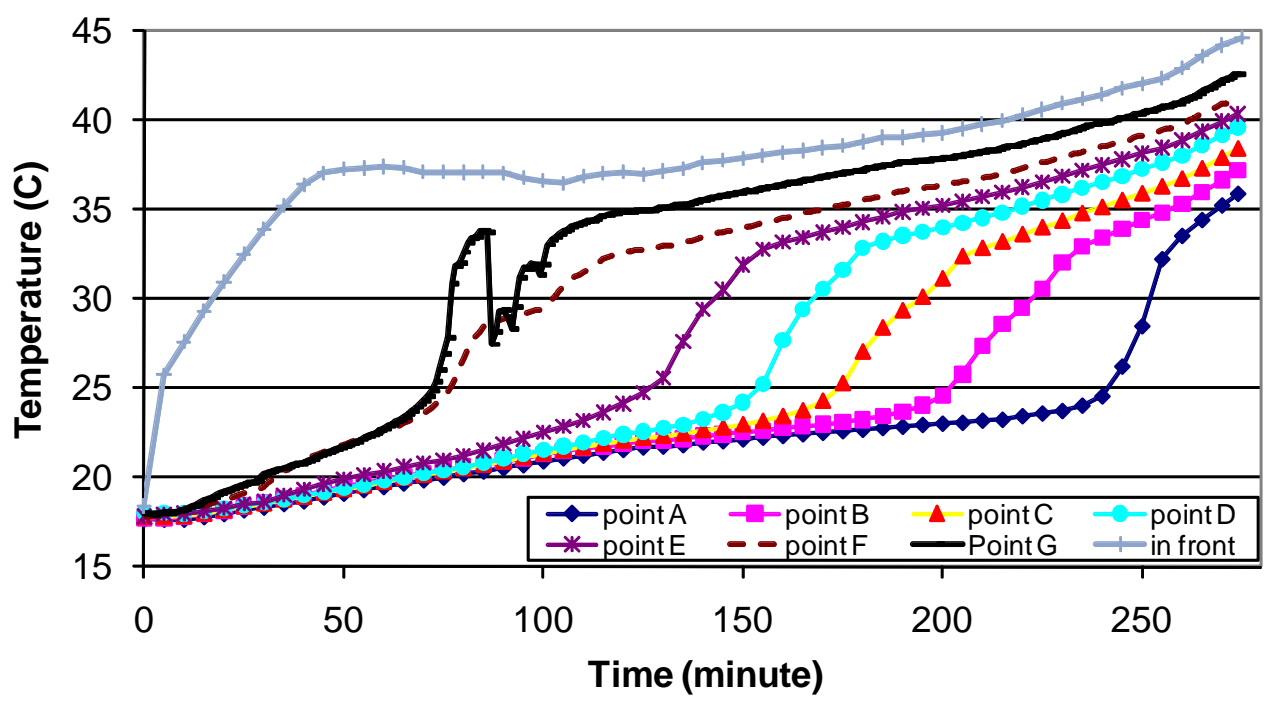

Figure 5 The temperature variation with time in the centre vertical line of PV/PCM system using RT27 with no fins for $750 \mathrm{Wm}^{-2}$ and surrounding average temperature $19^{\circ} \mathrm{C}$. 


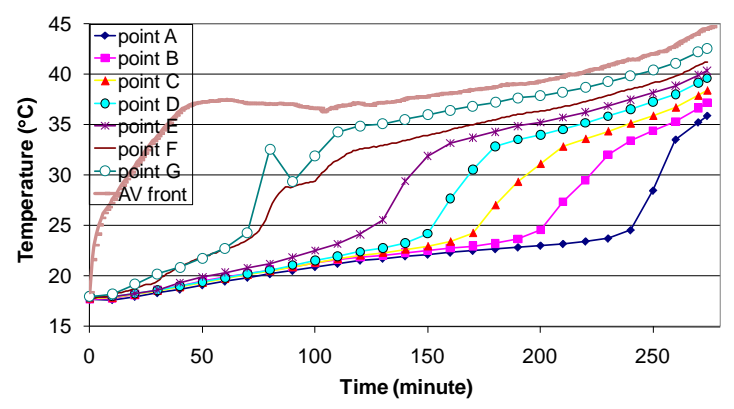

No fin module

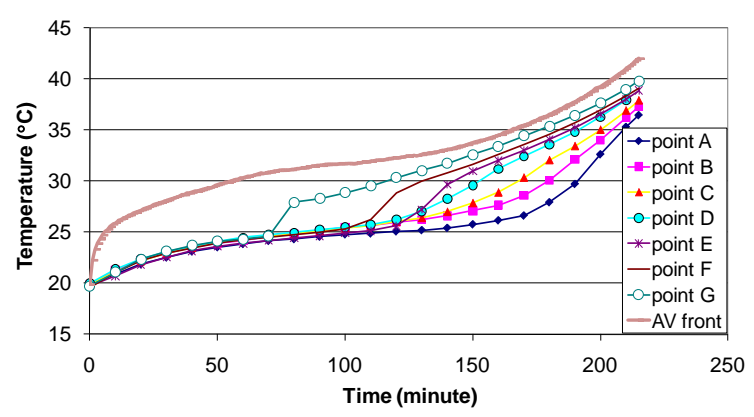

$24 \mathrm{~mm}$ fin spacing

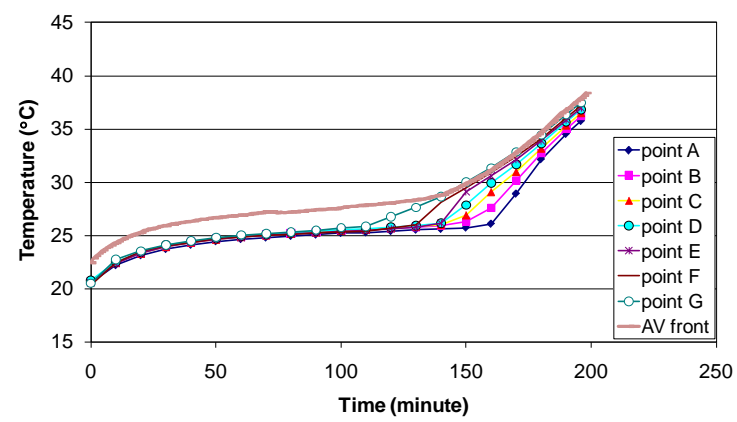

$8 \mathrm{~mm}$ fin spacing

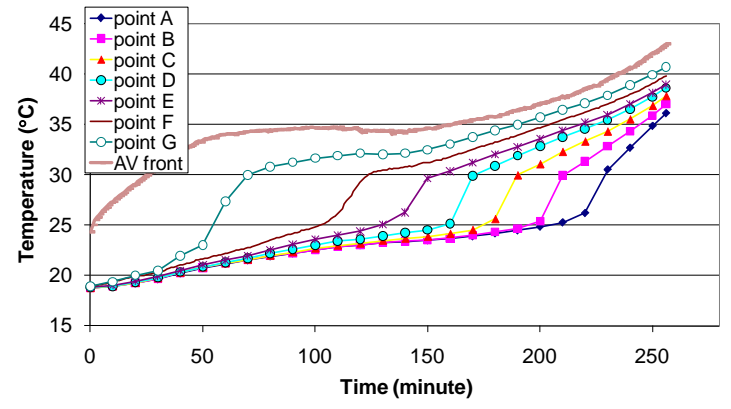

$33 \mathrm{~mm}$ fin spacing

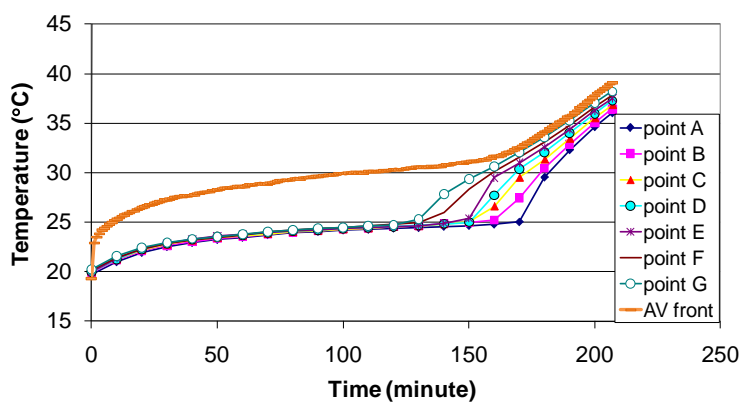

$12 \mathrm{~mm}$ fin spacing

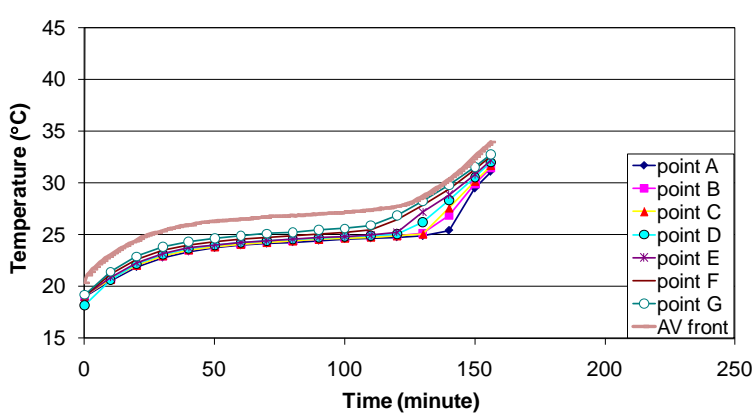

$4 \mathrm{~mm}$ fin spacing

Figure 6 The temperature variation with time from lower section point A to upper section point $\mathrm{G}$ in the centre of the PV/PCM system for varied fin intervals. 


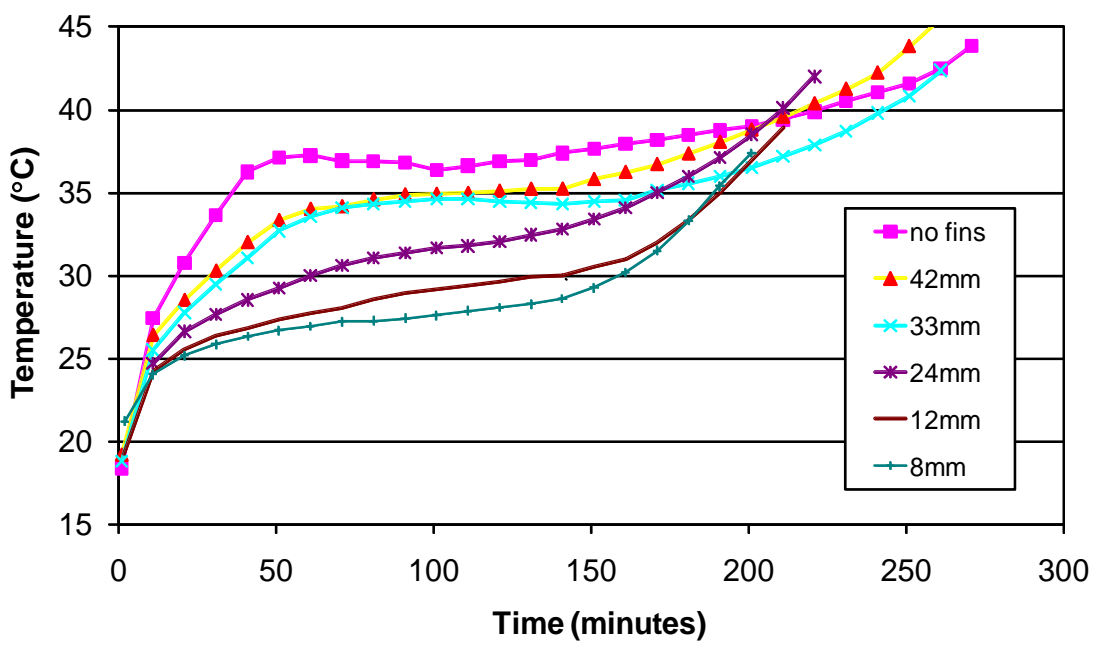

Figure $7 \quad$ The measured average front surface temperature for systems with different fin spacings 


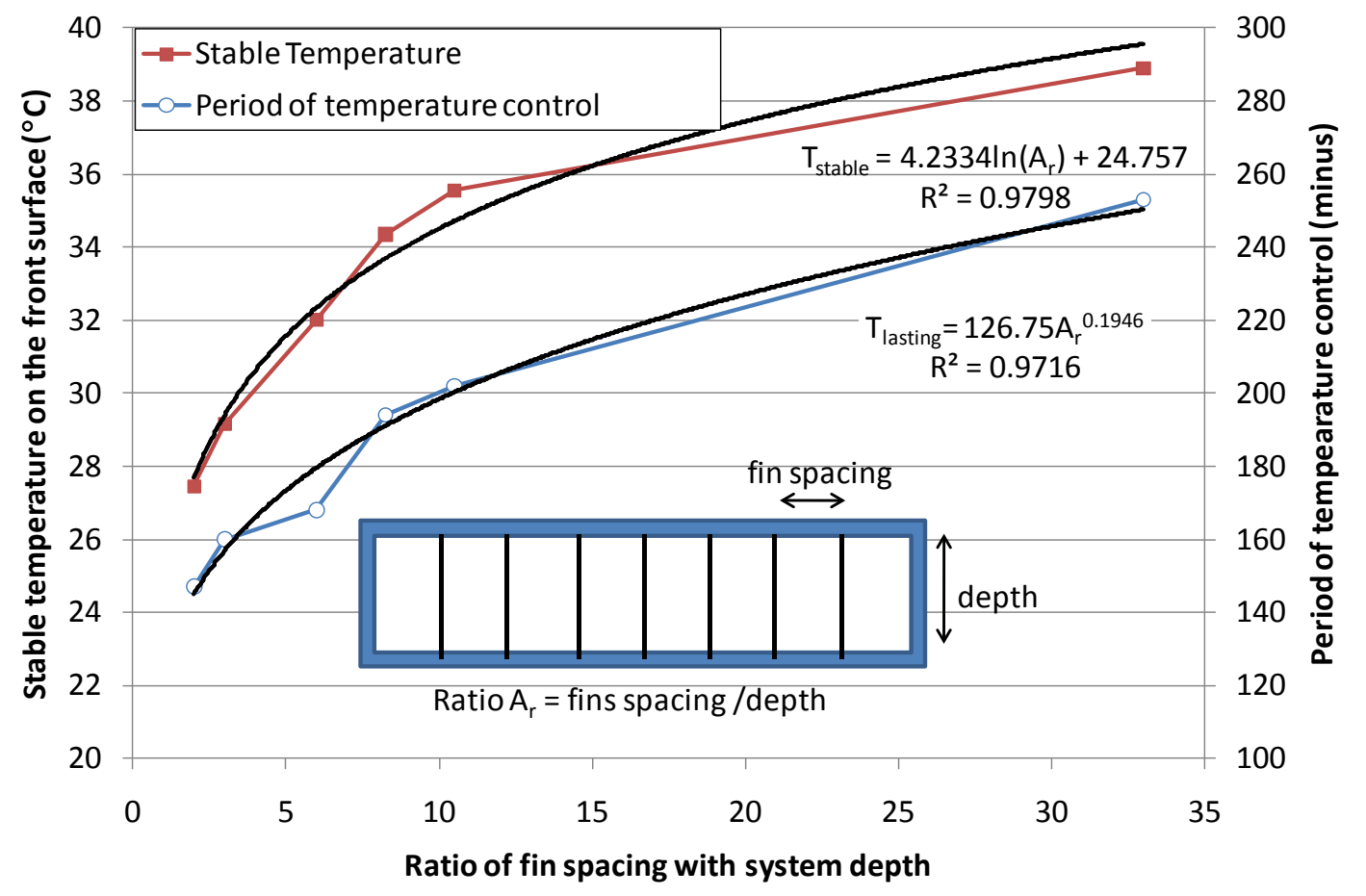

Figure 8 The temperature regulation with the ratio of fins spacing width on system

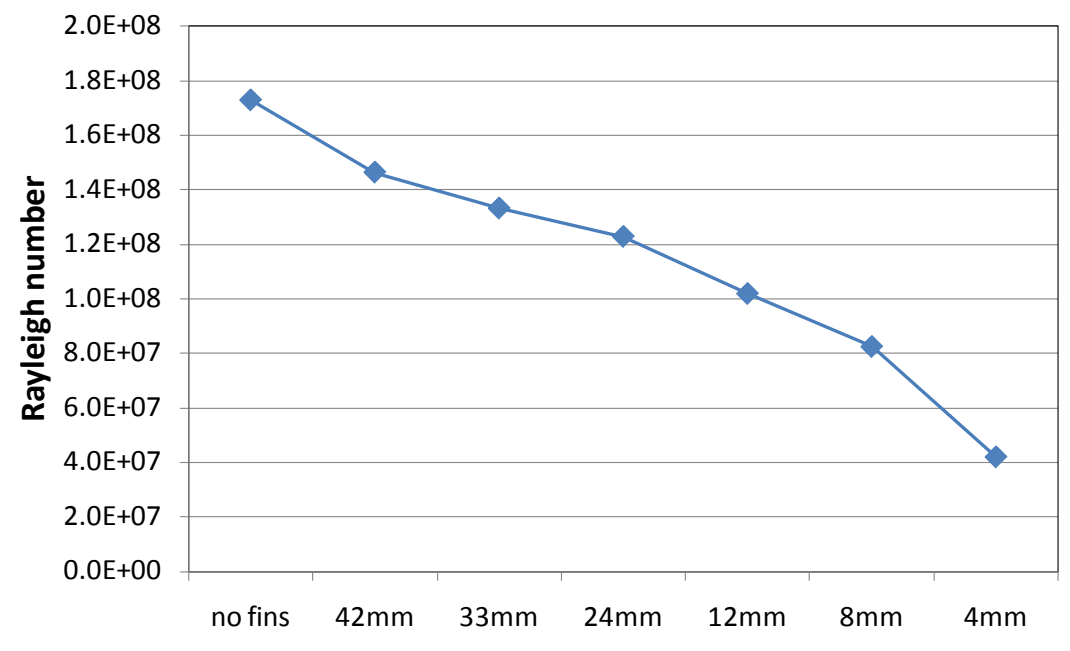

Fin intervals $(\mathrm{mm})$

Figure 9 Rayleigh number for PV/PCM system with different fin intervals 
Table 1 Thermophysical properties of Waksol A, RT27 and RT35 [9][10]

\begin{tabular}{|c|c|c|c|c|c|}
\hline & \multicolumn{3}{|c|}{ PCM (Liquid/Solid) } \\
\hline & & & WaksolA & RT27 & RT35 \\
\hline \multirow{14}{*}{ 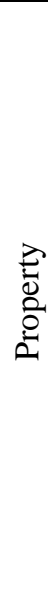 } & Density & & & & \\
\hline & Solid & $\mathrm{kg} \mathrm{m}^{-3}$ & 770 & 880 & 880 \\
\hline & Liquid & $\mathrm{kg} \mathrm{m}^{-3}$ & 760 & 760 & 760 \\
\hline & Specific heat capac & & & & \\
\hline & Solid & $\mathrm{J} \mathrm{m}^{-3} \mathrm{~K}^{-1}$ & 1771000 & 1566000 & 1584000 \\
\hline & Liquid & $\mathrm{J} \mathrm{m}^{-3} \mathrm{~K}^{-1}$ & 1848000 & 1800000 & 1824000 \\
\hline & Thermal conductivi & & & & \\
\hline & Solid & $\mathrm{W} \mathrm{m}^{-1} \mathrm{~K}^{-1}$ & 0.33 & 0.2 & 0.2 \\
\hline & Liquid & $\mathrm{W} \mathrm{m}{ }^{-1} \mathrm{~K}^{-1}$ & 0.31 & 0.2 & 0.2 \\
\hline & Melting temperatur & $e^{\circ} \mathrm{C}$ & $32-36$ & $25-28$ & 35 \\
\hline & Latent heat of fusio & $\mathrm{n} \mathrm{J} \mathrm{kg}^{-1}$ & 162000 & 184000 & 157000 \\
\hline & $\begin{array}{l}\text { Kinematic Viscosit } \\
\left(\text { at } 70^{\circ} \mathrm{C}\right)\end{array}$ & $y \mathrm{~mm}^{2} \mathrm{~s}^{-1}$ & N/A & 26.32 & 3.3 \\
\hline & Flash point & ${ }^{\circ} \mathrm{C}$ & & 164 & 178 \\
\hline & Volume expansion & $\%$ & & 10 & 10 \\
\hline
\end{tabular}


Figure $1 \quad$ PV/PCM assessment system with metal fins

Figure 2 Distribution of thermocouples within experimental PV/PCM system

Figure 3 The porosity formed in the central bulk of PCM Waksol A and RT35 when solidification occurred using a $-25^{\circ} \mathrm{C}$ temperature.

Figure $4 \quad$ Bubbles under fins formed during melting

Figure 5 The temperature variation with time in the centre vertical line of PV/PCM system using RT27 with no fins for $750 \mathrm{Wm}^{-2}$ and surrounding average temperature $19^{\circ} \mathrm{C}$.

Figure 6 The temperature variation with time from lower section point A to upper section point $\mathrm{G}$ in the centre of the PV/PCM system for varied fin intervals.

Figure $7 \quad$ The measured average front surface temperature for systems with different fin spacings

Figure 8 The temperature regulation with the ratio of fins spacing width on system

Figure 9 Rayleigh number for PV/PCM system with different fin intervals

Table 1 Thermophysical properties of Waksol A, RT27 and RT35 [9] 